\title{
Desempenho térmico de paredes de alvenaria protegidas com revestimento de compósitos de resíduos agrícolas
}

Fábio Severo da Rosa

fsevero@gmail.com

Universidade Federal de Santa Maria (UFSM), Santa Maria, Rio Grande do Sul, Brasil

Minéia Johann Scherer mineiaarq@gmail.com

Universidade Federal de Santa Maria (UFSM), Santa Maria, Rio Grande do Sul, Brasil

\author{
RESUMO
}

O artigo teve por objetivo avaliar a utilização de resíduos agrícolas em compósitos, com fins de isolamento térmico para uso em sistemas de vedações verticais em edificações, identificando o atendimento às normas pertinentes para a região sul do Brasil. A pesquisa teve como ponto de partida a análise dos resultados obtidos em pesquisas onde foram avaliados o desempenho térmico de resíduos agrícolas, tendo como foco o aproveitamento da casca de arroz e do sabugo de milho. Foi simulada uma parede de alvenaria em blocos vazados de concreto simples e de cerâmica, rebocada em ambas as faces com argamassa comum, considerando-se também o uso de uma camada de compósito sob a argamassa em uma das faces da parede. Os diferentes sistemas foram avaliados e comparados por meio dos valores de transmitância térmica e fator de ganho de calor solar. Os resultados obtidos comprovam a melhoria do desempenho das paredes com o uso dos compósitos considerados.
\end{abstract}

PALAVRAS-CHAVE: Resíduo agrícola. Compósito. Isolamento térmico. 


\section{INTRODUÇÃO}

Os projetistas e construtores enfrentam hoje um grande desafio que é reduzir o consumo de energia em todas as fases - construção, uso e demolição. $O$ Programa das Nações Unidas para o Meio Ambiente (UNEP, 2012), estima que os edifícios consomem cerca de $40 \%$ da energia global do mundo, sendo também responsáveis por cerca de $1 / 3$ das emissões de gases com efeito estufa de todo o planeta. Valores semelhantes são apresentados em levantamentos publicados pelo Departamento de Energia dos EUA (U.S. DEPARTMENT ENERGY, 2012), e pela Comissão Europeia (EUROPEAN COMISSION, 2016).

As medidas adotadas para reduzir os gastos com energia em aquecimento e refrigeração devem focar não só na melhoria da eficiência de aparelhos ou modificação do estilo de vida dos cidadãos, mas também na melhoria das propriedades de elementos usados no isolamento térmico nas construções (ASDRUBALI; D'ALESSANDRO e SCHIAVONI, 2015).

Com o aumento da demanda mundial por alimentos, se tem buscado o aumento das áreas cultivadas e da produtividade, com o uso de novas técnicas de produção, de equipamentos modernos e métodos de gestão do agronegócio. Entretanto, o cultivo e beneficiamento dessa produção têm gerado além de uma série de problemas ambientais, uma quantidade muito grande de resíduos, muitos dos quais não têm uma utilização adequada, sendo descartados, muitas vezes de forma incorreta.

A estimativa da geração de resíduos oriundos das agroindústrias associadas à agricultura para as culturas temporárias e permanentes mais representativas em termos de área cultivada no Brasil representa um total de 291 milhões de toneladas de resíduos (INSTITUTO DE PESQUISA ECONÔMICA APLICADA, 2012). O aproveitamento de subprodutos agrícolas é um assunto que tem despertado interesse de pesquisadores e empresas, devido a sua possibilidade de aplicações com finalidades diversas.

A estimativa da produção de arroz para 2017 alcança 11,6 milhões de toneladas (IBGE, 2017). O principal resíduo em seu processamento é a casca. Tem um alto volume e baixa densidade. É um material fibroso composto principalmente por celulose, lignina e sílica, insolúveis em água, com baixas propriedades nutritivas e resistência à intempéries (Genieva et al., 2008). Estimase que para cada hectare de cultura de arroz sejam produzidas de 4,0 a 6,0 toneladas de casca. Boa parte desse resíduo é depositado no solo sem qualquer tratamento e parte é queimada ao ar livre, com emissão de monóxido e dióxido de carbono (DELLA, KUHN e HOTZA, 2001).

O milho é produzido, principalmente para a alimentação, e o grão possibilita uma série de produtos industrializados. Entretanto, algumas partes da planta não possuem um uso direto, como o sabugo, o colmo (caule), folhas e palha, sendo subutilizados. Atualmente o sabugo é caracterizado como resíduo, sendo usado em baixa escala para alimentação animal, (FERREIRA, 2014) ou queimado (PINTO et al., 2012). A estimativa da produção de milho nos três estados da região sul do Brasil na safra 2016/17 atingiu 27.582.900 toneladas (COMPANHIA NACIONAL DE ABASTECIMENTO, 2017).

Diversas pesquisas apontam ser possível usar a casca de arroz, o sabugo de milho e uma série de outros materiais considerados resíduos, na formulação de compósitos para uso em revestimento interno de forros e paredes, na forma de painéis ou adicionados na camada de reboco para reduzir a transmissão de calor entre os ambientes, além de diversas outras finalidades. Além disso, são 
materiais totalmente renováveis, regionais e de baixo impacto ambiental (MENDES et al., 2010; KORJENIC et al., 2011; PANYAKAEW, S.; FOTIOS, S, 2011; ROSA et al., 2015).

O objetivo deste trabalho foi avaliar através de simulações, a utilização de resíduos agrícolas, especificamente a casca de arroz e sabugos de milho em compósitos, com fins de isolamento térmico, identificando o atendimento às normas pertinentes para edificações na região sul do Brasil, correspondente à zona bioclimática 2 .

\section{REFERENCIAL TEÓRICO}

A presente revisão bibliográfica visa a compreensão do funcionamento da isolação térmica de uma parede de alvenaria revestida com camadas de argamassa e compósito. Para que seja possível analisar os resultados é importante discorrer sobre o comportamento dos isolantes térmicos, a utilização de resíduos agroindustriais na construção civil e as normas para edificações.

\section{ISOLANTES TÉRMICOS}

Os isolantes térmicos são escolhidos de acordo com aspectos econômicos, funcionais e de segurança. Sua principal função é de reduzir a taxa de transferência de calor entre um sistema e o meio (NEIRA, 2005). O isolante térmico para ser considerado bom, deve possuir baixo coeficiente de condutividade térmica, ter boa resistência mecânica, baixa difusividade térmica, ser de fácil aplicação e baixo custo (CRUZ, FERREIRA e MARINHO, 2009). Os principais materiais isolantes usados no Brasil são: lã de vidro, lã de rocha e poliuretano (ROSA et al., 2015).

A condutividade térmica, designada no texto por ?], é uma propriedade física de um material, no qual se verifica um fluxo de calor constante, com densidade de $1 \mathrm{~W} / \mathrm{m} 2$, quando submetido a um gradiente de temperatura uniforme de $1 \mathrm{~K}$

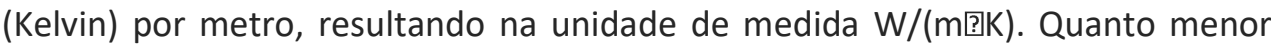
for o valor da condutividade térmica de um material, mais isolante será (ABNT, 2005a).

A resistência térmica $(R)$ de um material mede a sua capacidade de reduzir a troca de calor, sendo expressa em $(\mathrm{m} 2 \mathrm{l} \mathrm{K}) / \mathrm{W}$. Assim, quanto maior for a resistência térmica do material, melhor é a sua capacidade de isolação térmica. Em uma camada homogênea de material sólido, a resistência térmica é igual a e/[? onde "e" corresponde a espessura da camada do material (ABNT, 2005á; BORGNAKKE, C.; SONNTAG, R. E., 2013). A resistência térmica total de ambiente a ambiente (1), ilustrada na figura 1, é dada por

$$
\mathrm{R}_{\mathrm{T}}=\mathrm{Rse}+\mathrm{Rt}+\mathrm{Rsi}
$$


Figura 1 - (a) Resistência térmica de uma camada homogênea; (b) resistência térmica total

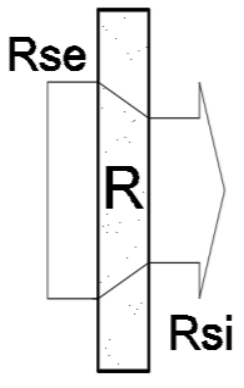

(a)

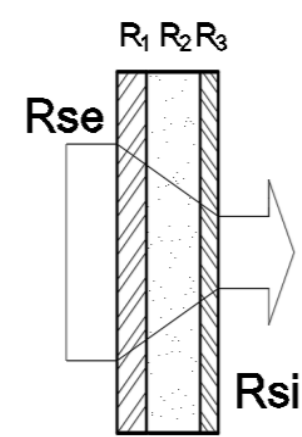

(b)
Rse - Resistência

superficial externa.

Rsi - Resistência

superficial interna.

$\mathrm{R}$ - Resistência térmica

do material.

Fonte: Autoria própria (2017)

Rt corresponde à resistência térmica total, de superfície à superfície, de um componente plano constituído por $\mathrm{n}$ camadas homogêneas, perpendiculares ao fluxo de calor, obtida pela soma das resistências térmicas de cada camada. Rse e Rsi são as resistências superficiais externa e interna, tendo valores médios

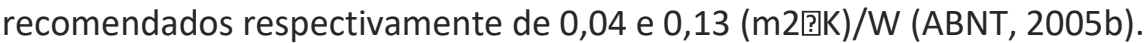

A transmitância térmica $(U)$ ou coeficiente global de transferência de calor corresponde ao inverso da resistência térmica, sendo expressa em W / (m2 [?KK). Essa medida corresponde a uma propriedade dos componentes construtivos relacionada à permissão da passagem de energia térmica, estando relacionada à espessura do componente e à condutividade térmica dos seus materiais constituintes (ABNT, 2005b).

O fator de ganho de calor solar ou simplesmente fator solar (FSO), corresponde ao quociente da taxa de radiação solar transmitida através de um componente opaco pela taxa de radiação solar total incidente sobre a superfície externa do mesmo, sendo expresso em \% e dado pela expressão (2) (ABNT, 2005b).

FSo $=4 \cdot U \cdot \alpha$

Onde $U$ corresponde à transmitância térmica do componente e $\alpha$ é a absortância à radiação solar, sendo função da cor da superfície exposta, tendo valores apresentados em tabela para vários tipos de superfícies e cores (ABNT, 2005b, p. 8).

\section{RESÍDUOS AGROINDUSTRIAIS}

O Brasil é conhecido por seu grande potencial de recursos renováveis tais como produtos agrícolas e florestais. Como consequência se tem uma grande diversidade de resíduos como o bagaço de cana-de-açúcar, a fibra de coco, a casca de arroz, a casca da aveia e aparas de madeira. Conforme Tamanini e Hauly (2004) a população produz milhões de toneladas de resíduos agroindustriais anualmente. A América Latina produz aproximadamente 500 milhões de toneladas/ano de subprodutos agroindustriais, sendo que o Brasil produz quase a 
metade deste montante. Na maioria das vezes, esses rejeitos são dispensados no meio ambiente, provocando um acúmulo excessivo de matéria orgânica. Esses resíduos podem ser convertidos em energia, ou então usados na criação de produtos com finalidades diversas.

De acordo com estatísticas da FAO (Food and Agriculture Organization of the United Nations), o Brasil é o nono maior produtor de arroz (Oryza sativa L.) do mundo. A produção está localizada, principalmente, no estado do Rio Grande do Sul, com 66,5\% da produção. A estimativa da produção de arroz para 2016 alcança 12,2 milhões de toneladas (FAO, 2012; IBGE, 2015). A casca de arroz é um dos mais abundantes resíduos agrícolas. Segundo Amick (1982) as cascas representam $23 \%$ dos grãos. Estima-se que para cada hectare de cultura de arroz sejam produzidas de 4,0 a 6,0 toneladas de casca (VIEIRA, 2012). A casca de arroz pode variar sua composição de acordo com a variedade plantada, clima e das condições do solo, sendo composta principalmente de celulose (50\%), lignina (30\%) e resíduo orgânico (20\%), possuindo baixa densidade e elevado volume (FERNANDES, 2006; BEZERRA, 2010). A casca de arroz pode ser usada como combustível por apresentar um alto poder calorífico e um alto conteúdo de materiais voláteis (ARMESTO et al., 2002). A queima controlada é bastante usada na geração de energia térmica inclusive no próprio beneficiamento do arroz. Entretanto isso gerado uma grande quantidade de cinzas, um resíduo de difícil degradação e com alto teor de silício que disposto de forma inadequada, pode causar danos ao meio ambiente e aos seres humanos (CHAVES, et al., 2009).

O milho é o cereal mais cultivado no mundo, sendo utilizado como alimento humano, animal e matéria-prima para a indústria, pela quantidade e natureza das reservas nos grãos (BARBOSA, 2011). No contexto nacional o milho é uma cultura tradicional que ocupa uma posição significativa, quanto ao valor da produção agropecuária, área cultivada e volume produzido, dando ênfase nas regiões sul, sudeste e centro-oeste (TURCO, 2011). O Brasil está entre os maiores produtores de milho, junto com Estados Unidos, China e Portugal (PINTO et al., 2012). De acordo com dados da Companhia Nacional de Abastecimento (CONAB) a produção de milho nos três estados da região sul na safra 2015/16 totalizou 23.089.700 toneladas (COMPANHIA NACIONAL DE ABASTECIMENTO, 2016).

Os resíduos da cultura e processamento do milho são o sabugo, colmo (caule), folhas e palha, sendo gerada uma quantidade de 2,3 toneladas de resíduos para cada tonelada colhida (VIEIRA, 2012).

Vários pesquisadores têm concentrado esforços no sentido de estudar o potencial da aplicação de diversos materiais orgânicos no campo da construção civil. Esses pesquisadores têm obtido resultados otimistas, permitindo um equilíbrio desejável em termos de qualidade do ponto de vista técnico, de custo e de sustentabilidade (PINTO et al.,2012). As propostas aproximam-se do conceito Ecologia Industrial onde o que é considerado resíduo em um processo produtivo é aproveitado como insumo em outro processo (TEIXEIRA; SANTOS JUNIOR; COUTO, 2016).

Mishra, Chakraverty e Banerjee (1986) pesquisaram e aplicaram a casca de arroz em placas de isolamento, materiais de embalagem e cerâmicos. Os autores

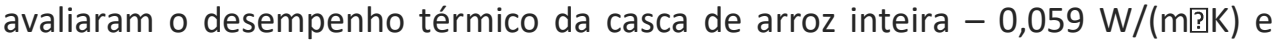

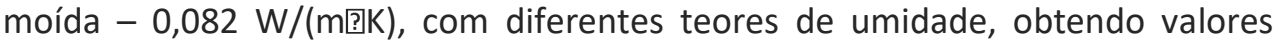
menores de condutividade térmica para as cascas inteiras.

Rout e Satapathy (2012) com auxílio do método dos elementos finitos, avaliaram a condutividade térmica de compósitos elaborados com resina epóxi, 
com adição de casca de arroz em diferentes proporções, constatando que da resina pura até $6,5 \%$ de casca de arroz, ocorreu uma redução média de $8,6 \%$ no

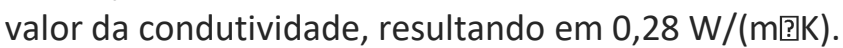

Paiva, et al. (2012) propuseram um método para avaliar o desempenho térmico de painéis de diferentes espessuras elaborados com um compósito à base de sabugo de milho moído, avaliando a condutividade térmica, obtendo $0,043 \mathrm{~W} /(\mathrm{m}$ 茢 $)$.

\section{DESEMPENHO TÉRMICO DE EDIFICAÇÕES}

A escolha dos materiais construtivos está relacionada à questões de resistência mecânica, de segurança e econômicos, deixando-se muitas vezes as questões de desempenho térmico para um plano secundário. Os custos de aquecimento no inverno e refrigeração no verão são muito elevados. Um dos grandes desafios é o de melhorar o desempenho energético dos edifícios, considerando a crescente ênfase social dada às questões ambientais, a eliminação de resíduos, e ao esgotamento dos recursos não-renováveis (MATIBAOUCHE et al., 2014).

As exigências de conforto térmico estão relacionadas com o funcionamento do corpo humano. Havendo a sensação de frio ou calor, significa que o organismo está perdendo ou ganhando calor para que a sua temperatura interna se mantenha na ordem de $370 \mathrm{C}$. Partindo desse princípio, das condições climáticas e das características térmicas dos materiais usados no projeto e construção dos ambientes a serem ocupados pelas pessoas, se tem as condições necessárias para se projetar artefatos e ambientes que atendam as exigências de conforto térmico (FROTA e SCHIFFER, 2003).

As condições climáticas se alteram para locais distintos. O território brasileiro, pela sua extensão geográfica e grandes diferenças no relevo e clima, foi dividido em oito zonas bioclimáticas homogêneas quanto ao clima. Para cada zona foram definidas recomendações técnico-construtivas para otimizar o desempenho térmico das edificações. A zona bioclimática 2, objeto desse estudo, compreende boa parte dos estados do Rio Grande do Sul, Santa Catarina, Paraná e alguns pontos do estado de São Paulo e Minas Gerais (ABNT, 2005c).

Os requisitos de desempenho térmico mínimo são estabelecidos no Brasil através da norma ABNT NBR 15575-4:2013, para sistemas de vedações verticais e ABNT NBR 15575-5:2013 para sistemas de cobertura. Um dos critérios adotados para avaliação do desempenho térmico desses sistemas é através da transmitância térmica $(U)$ de paredes externas ou fluxo térmico descendente em coberturas. No caso de paredes externas, para a zona bioclimática 2, o valor estabelecido é $U \leq 2,5 \mathrm{~W} /$ ( $\mathrm{m} 2$ ?]K) (ABNT, 2013a). No caso da variável fator solar, é recomendado na norma ABNT NBR15220-3:2005 o valor FSO $\leq 5,0 \%$ (ABNT, 2005c).

\section{METODOLOGIA}

Esta pesquisa é de natureza aplicada com uma abordagem qualitativa e quantitativa (GIL, 2010, MIGUEL, 2012). Em relação aos seus objetivos, apresenta caráter exploratório. Quanto aos procedimentos técnicos, foram usados: pesquisa bibliográfica em artigos científicos, artigos técnicos, normas técnicas e 
livros; simulação quando alguns compósitos foram comparados quanto as suas propriedades isolantes em relação às exigências de desempenho térmico, tendo por base os dados apresentados nos artigos.

Foram definidas duas situações: uma parede de alvenaria em blocos vazados de concreto simples rebocada em ambas as faces com uma camada de reboco, usando argamassa comum (espessura $-2 \mathrm{~cm}$ ); uma parede de alvenaria idêntica, substituindo os blocos vazados de concreto simples por blocos vazados de cerâmica nas mesmas dimensões. Para os dois casos foi simulada uma alteração no revestimento da face interna onde adotou-se uma camada de argamassa comum com espessura de $1 \mathrm{~cm}$ e uma camada de compósito com espessura de $1 \mathrm{~cm}$, mantendo-se a face externa com uma camada de reboco, usando argamassa comum com espessura de $2 \mathrm{~cm}$. Em todos os casos considerou-se que os blocos foram assentados com argamassa comum com espessura de $1 \mathrm{~cm}$ (Figura 2), compondo o sistema avaliado. As dimensões dos blocos usados estão ilustradas na figura 3.

Figura 2 - Detalhes da parede de blocos vazados de concreto ou cerâmico

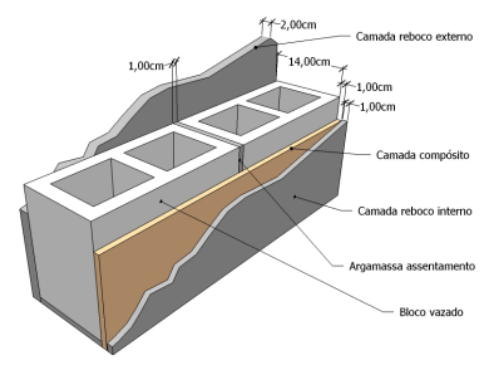

Fonte: Autoria própria (2017)

Figura 3 - Bloco vazado e respectivas dimensões

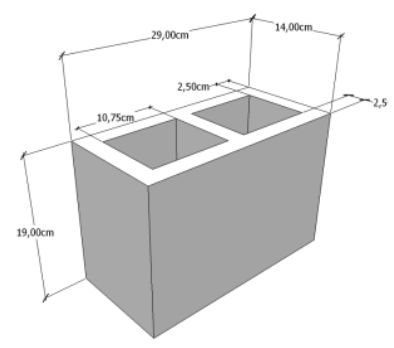

Fonte: Autoria própria (2017)

Foram identificados e considerados na pesquisa quatro experimentos onde os autores determinaram os valores de condutividade térmica de suas formulações (Quadro 1). 
Quadro 1 - Elementos componentes da resistência térmica total para os dois tipos de parede adotados no estudo, sem e com o uso dos compósitos adotados na pesquisa

\begin{tabular}{|c|c|c|}
\hline Autor(es) & Material usado & $\begin{array}{c}\text { Condutividade térmica }(\boldsymbol{\lambda}) \\
\mathbf{W} / \mathbf{m K}\end{array}$ \\
\hline $\begin{array}{c}\text { Mishra, Chakraverty e } \\
\text { Banerjee (1986) }\end{array}$ & Casca de arroz inteira & 0,059 \\
\cline { 2 - 3 } Casca de arroz moída & 0,082 \\
\hline Rout e Satapathy (2012) & $\begin{array}{c}\text { Casca de arroz e } \\
\text { resina epóxi }\end{array}$ & 0,28 \\
\hline Paiva, et al. (2012) & $\begin{array}{c}\text { Sabugo de milho } \\
\text { triturado e } \\
\text { cola de madeira }\end{array}$ & 0,059 \\
\hline
\end{tabular}

Fonte: Autoria própria (2017)

Os materiais usados nos componentes dos sistemas comparados serviram para avaliar seu desempenho térmico seguindo os métodos de cálculo descritos na norma ABNT NBR 15220-2: 2005, que trata do desempenho térmico de edificações (ABNT, 2005b). Os valores calculados das áreas (A1, A2 e A3) de cada seção, das resistências térmicas de superfície à superfície para cada seção (R1, R2 e R3), das resistências térmicas da parede e total para cada um dos sistemas, estão representados no quadro 2 .

Quadro 2 - Elementos componentes da resistência térmica total para os dois tipos de parede adotados no estudo, sem e com o uso dos compósitos adotados na pesquisa

\begin{tabular}{|c|c|c|c|c|c|c|c|c|c|c|}
\hline \multirow[t]{2}{*}{$\begin{array}{c}\text { SISTEMA } \\
\text { AVALIADO }\end{array}$} & \multicolumn{3}{|c|}{$\begin{array}{c}\text { Áreas das } \\
\text { seções }\left(\mathrm{m}^{2}\right)\end{array}$} & \multicolumn{3}{|c|}{$\begin{array}{c}\text { Resistência } \\
\text { térmica de } \\
\text { superfície à } \\
\text { superfície para } \\
\text { cada seção } \\
\left(\mathrm{m}^{2} \cdot \mathrm{K}\right) / \mathrm{W}\end{array}$} & \multicolumn{2}{|c|}{$\begin{array}{c}\text { Resistência } \\
\text { superficial } \\
\text { externa e } \\
\text { interna } \\
\left(\mathrm{m}^{2} \cdot \mathrm{K}\right) / \mathrm{W}\end{array}$} & \multirow[t]{2}{*}{$\begin{array}{c}\text { Resistê } \\
\text { ncia } \\
\text { térmica } \\
\text { da } \\
\text { parede } \\
\left(\mathrm{m}^{2} \cdot \mathrm{K}\right) / \\
\mathrm{W} \\
\mathrm{Rt}\end{array}$} & \multirow[t]{2}{*}{$\begin{array}{c}\text { Resist } \\
\text { ência } \\
\text { térmi } \\
\text { ca } \\
\text { total } \\
\left(\mathrm{m}^{2} \cdot \mathrm{K}\right. \\
\mathrm{JW} \\
\mathrm{RT}_{\mathrm{T}} \\
\end{array}$} \\
\hline & A1 & $\mathrm{A} 2$ & A3 & $\mathrm{R} 1$ & $\mathrm{R} 2$ & R3 & Rse & Rsi & & \\
\hline $\begin{array}{l}\text { Parede de } \\
\text { blocos } \\
\text { vazados de } \\
\text { concreto }\end{array}$ & 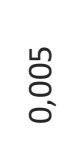 & 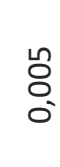 & 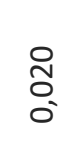 & $\begin{array}{l}\hat{n} \\
\stackrel{n}{0} \\
0^{\prime}\end{array}$ & $\begin{array}{l}\stackrel{n}{\sim} \\
\stackrel{-}{-1} \\
0\end{array}$ & 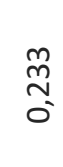 & $\begin{array}{l}\text { 寸 } \\
\text { ' }\end{array}$ & 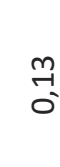 & $\begin{array}{l}\text { N} \\
\stackrel{1}{*} \\
0\end{array}$ & 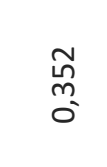 \\
\hline $\begin{array}{c}\text { Parede de } \\
\text { blocos } \\
\text { vazados de } \\
\text { concreto }- \\
\text { compósito } 1 \\
(0,059 \\
\mathrm{W} / \mathrm{mK})\end{array}$ & $\begin{array}{l}\text { ํㅗ } \\
\text { ᄋ̊ } \\
\text { ó }\end{array}$ & $\begin{array}{l}\text { 오 } \\
\text { 8 } \\
\text { o' }\end{array}$ & ర్స & $\begin{array}{l}\hat{F} \\
\stackrel{-}{n} \\
0\end{array}$ & $\begin{array}{l}0 \\
\stackrel{0}{N} \\
0\end{array}$ & $\begin{array}{l}\text { চ } \\
\text { m̃ } \\
0\end{array}$ & $\begin{array}{l}\text { ठ } \\
\text { O' }\end{array}$ & $\stackrel{m}{\rightarrow}$ & $\begin{array}{l}\text { ํㅗ } \\
\text { ñ } \\
\text { ó }\end{array}$ & $\begin{array}{l}\text { तี } \\
\text { ஸે } \\
0\end{array}$ \\
\hline $\begin{array}{c}\text { Parede de } \\
\text { blocos } \\
\text { vazados de } \\
\text { concreto }- \\
\text { compósito } 2 \\
(0,082 \\
\mathrm{W} / \mathrm{mK})\end{array}$ & 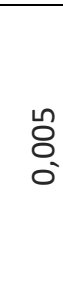 & $\begin{array}{l}\text { ำ } \\
\text { ᄋ̊ } \\
\text { ○' }\end{array}$ & రి & ڤ̃ & $\stackrel{\infty}{N}$ & 守 & $\begin{array}{l}\text { ठ } \\
\text { O }\end{array}$ & $\stackrel{m}{-}$ & $\begin{array}{l}\text { ̃̃ } \\
\text { ก̃ } \\
0\end{array}$ & 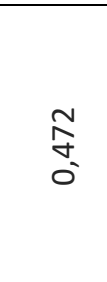 \\
\hline
\end{tabular}




\begin{tabular}{|c|c|c|c|c|c|c|c|c|c|c|}
\hline $\begin{array}{c}\text { Parede de } \\
\text { blocos } \\
\text { vazados de } \\
\text { concreto - } \\
\text { compósito } 3 \\
(0,28 \mathrm{~W} / \mathrm{mK})\end{array}$ & $\begin{array}{l}\text { ஜ̊ } \\
\text { О. }\end{array}$ & $\begin{array}{l}\text { 号 } \\
0 \\
0\end{array}$ & $\begin{array}{l}\text { Dे } \\
0 \\
0 \\
0\end{array}$ & 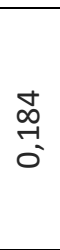 & $\begin{array}{l}\text { 告 } \\
\text { - }\end{array}$ & $\begin{array}{l}\stackrel{O}{0} \\
\stackrel{N}{0}\end{array}$ & $\begin{array}{l}\text { D } \\
0 \\
0\end{array}$ & $\begin{array}{l}m \\
\text { - } \\
\text { - }\end{array}$ & $\begin{array}{l}\underset{I}{\sim} \\
\text { o }\end{array}$ & $\begin{array}{l}\vec{\infty} \\
\stackrel{0}{m} \\
0^{-}\end{array}$ \\
\hline $\begin{array}{l}\text { Parede de } \\
\text { blocos } \\
\text { vazados de } \\
\text { concreto - } \\
\text { compósito } 4 \\
(0,043 \\
\text { W/mK }) \\
\end{array}$ & 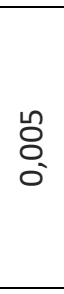 & $\begin{array}{l}\stackrel{2}{\circ} \\
0 \\
0\end{array}$ & $\begin{array}{l}\stackrel{\text { I }}{0} \\
\text { o. }\end{array}$ & 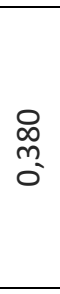 & $\begin{array}{c}\text { } \\
\text { m} \\
\text { ó }\end{array}$ & $\begin{array}{l}\text { 占 } \\
0\end{array}$ & $\begin{array}{l}\text { D } \\
\text { O' }\end{array}$ & 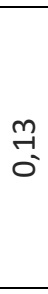 & \begin{tabular}{l}
0 \\
\multirow{\sigma}{*}{} \\
0
\end{tabular} & $\begin{array}{l}0 \\
\infty \\
0 \\
0 \\
0\end{array}$ \\
\hline $\begin{array}{l}\text { Parede de } \\
\text { blocos } \\
\text { vazados de } \\
\text { cerâmica }\end{array}$ & $\begin{array}{l}\text { थ̊ } \\
\text { O. }\end{array}$ & $\begin{array}{l}\text { थ̊ } \\
\stackrel{0}{\circ}\end{array}$ & $\begin{array}{l}\text { 尺े } \\
\text { ర్ } \\
\text { - }\end{array}$ & $\begin{array}{l}\hat{n} \\
\text { 号 }\end{array}$ & $\begin{array}{l}\text { 号 } \\
\text { : }\end{array}$ & $\begin{array}{l}\stackrel{0}{\stackrel{0}{0}} \\
\text { ó }\end{array}$ & $\begin{array}{l}\text { D } \\
0 \\
0\end{array}$ & $\begin{array}{c}m \\
\text { - }\end{array}$ & $\begin{array}{l}\stackrel{\infty}{N} \\
\text { o }\end{array}$ & 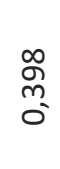 \\
\hline $\begin{array}{l}\text { Parede de } \\
\text { blocos } \\
\text { vazados de } \\
\text { cerâmica - } \\
\text { compósito } 1 \\
(0,059 \\
\text { W/mK) }\end{array}$ & $\begin{array}{l}\text { थ̊ } \\
0 \\
0\end{array}$ & $\begin{array}{l}\text { 号 } \\
0 \\
0\end{array}$ & $\begin{array}{l}\text { §ิ } \\
0 \\
0\end{array}$ & $\begin{array}{l}\stackrel{i}{m} \\
\text { o. } \\
0^{\prime}\end{array}$ & $\begin{array}{l}\stackrel{n}{n} \\
0 \\
0\end{array}$ & \begin{tabular}{l}
$\vec{I}$ \\
\multirow{I}{*}{}
\end{tabular} & $\begin{array}{l}\text { to } \\
0\end{array}$ & $\begin{array}{l}m \\
\text { ? } \\
\text { - }\end{array}$ & 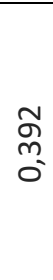 & $\begin{array}{l}\text { ర్ } \\
\stackrel{0}{0} \\
0\end{array}$ \\
\hline $\begin{array}{c}\text { Parede de } \\
\text { blocos } \\
\text { vazados de } \\
\text { cerâmica - } \\
\text { compósito } 2 \\
(0,082 \\
\text { W/mK }) \\
\end{array}$ & $\begin{array}{l}\text { थ̊ } \\
\stackrel{0}{0}\end{array}$ & 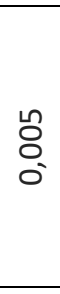 & $\begin{array}{l}\text { 尺्. } \\
\text { O. } \\
\text { - }\end{array}$ & $\begin{array}{c}\stackrel{2}{N} \\
\text { ó }\end{array}$ & $\begin{array}{l}\text { ¿ } \\
\text { ñ } \\
\text { ó }\end{array}$ & 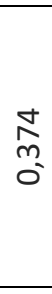 & $\begin{array}{l}\text { D } \\
0\end{array}$ & $\begin{array}{c}m \\
\text { ? } \\
\text { - }\end{array}$ & 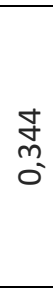 & $\begin{array}{l}\text { 吾 } \\
\text { o }\end{array}$ \\
\hline $\begin{array}{c}\text { Parede de } \\
\text { blocos } \\
\text { vazados de } \\
\text { cerâmica - } \\
\text { compósito } 3 \\
(0,28 \mathrm{~W} / \mathrm{mK}) \\
\end{array}$ & $\begin{array}{l}\text { L̊ } \\
\text { О. }\end{array}$ & $\begin{array}{l}\text { Ln } \\
\stackrel{0}{\circ}\end{array}$ & $\begin{array}{l}\text { 尺्. } \\
\text { O. } \\
\text {. }\end{array}$ & 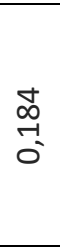 & $\begin{array}{l}\text { İ } \\
\text { ․ }\end{array}$ & $\begin{array}{c}\widehat{\infty} \\
\stackrel{0}{0} \\
\text { o }\end{array}$ & $\begin{array}{l}\text { D } \\
0\end{array}$ & $\stackrel{m}{\mathfrak{m}_{0}}$ & $\begin{array}{l}\stackrel{\mathscr{L}}{N} \\
\text { ó }\end{array}$ & $\begin{array}{l}\stackrel{0}{N} \\
\stackrel{0}{0}\end{array}$ \\
\hline $\begin{array}{c}\text { Parede de } \\
\text { blocos } \\
\text { vazados de } \\
\text { cerâmica }- \\
\text { compósito } 4 \\
(0,043 \\
\text { W/mK })\end{array}$ & $\begin{array}{l}\text { Ln } \\
\stackrel{0}{\circ}\end{array}$ & $\begin{array}{l}\text { L } \\
\stackrel{0}{0}\end{array}$ & 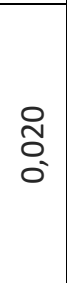 & 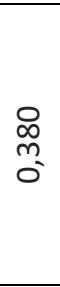 & $\begin{array}{l}\underset{f}{\vec{y}} \\
\underset{0}{+}\end{array}$ & $\begin{array}{l}\text { † } \\
\text { @ } \\
0\end{array}$ & $\begin{array}{l}\text { D } \\
\text { O }\end{array}$ & $\stackrel{m}{\stackrel{m}{\sigma}}$ & $\begin{array}{l}\text { 号 } \\
\text { ó }\end{array}$ & $\begin{array}{l}\text { Uి } \\
\text { o }\end{array}$ \\
\hline
\end{tabular}

Fonte: Autoria própria (2017)

As três seções, denominadas 1,2 e 3 correspondem respectivamente a: reboco interno, argamassa de assentamento e reboco externo; reboco interno, reforços transversais do bloco de concreto ou bloco de cerâmica e reboco externo; reboco interno, duas laterais do bloco, espaço de ar interno ao bloco e reboco externo. Nos sistemas em que foram adotados os diferentes compósitos, a camada de reboco interno $(1 \mathrm{~cm})$ é sobreposta à camada de compósito $(1 \mathrm{~cm})$.

A condutividade térmica (回) dos materiais componentes nos dois casos são: argamassa comum $-1,15 \mathrm{~W} /(\mathrm{m}$ [?K $)$, cerâmica $-0,90 \mathrm{~W} /(\mathrm{m}$ [? $\mathrm{K})$, concreto normal $1,75 \mathrm{~W} /(\mathrm{m}$ ]K $)$, resistência térmica de câmaras de ar não ventiladas $-0,17$ m2قK/W (ABNT, 2005b, p. 8-9); camada interna de compósito - valores obtidos 
nos quatro experimentos. No cálculo da resistência térmica total de ambiente a ambiente adotou-se a resistência superficial interna Rsi - 0,13 (m2]K)/W e externa Rse - 0,04 (m2 قek)/W (ABNT, 2005b, p. 7).

Os resultados foram avaliados através da comparação dos valores de transmitância térmica (U) de paredes externas e o fator solar (FSO) de elementos opacos (parede leve), considerando-se as situações: parede de blocos vazados de concreto e de cerâmica, rebocadas em ambas as faces com argamassa comum com e sem uma camada de compósito na face interna, observando os limites estabelecidos para a zona bioclimática 2. No cálculo de FSo considerou-se acabamento com reboco claro com valor de absortância à radiação solar $\alpha=0,40$ (ABNT, 2005b, p. 8).

\section{DISCUSSÃO DOS RESULTADOS}

Os resultados obtidos estão agrupados no quadro 3 , onde constam os valores resultantes dos cálculos de resistência térmica total (RT) de ambiente a ambiente, da transmitância térmica (U) e do fator de ganho de calor solar (FSO), para os diferentes sistemas comparados.

Verifica-se no quadro 3 que os dois sistemas analisados - parede dos blocos vazados de concreto ou cerâmica usando reboco externo e interno com argamassa comum, não atendem à exigência quanto à transmitância térmica, uma vez que essa grandeza extrapola o limite exigido, que segundo a norma da ABNT, 2013a, p.27 para a zona bioclimática 2 é $U \leq 2,5$. Entretanto os valores correspondentes ao fator solar estão dentro dos limites admissíveis. Constata-se também que ao adotar-se nos dois sistemas, uma camada de compósito, somente num dos casos não atende o valor mínimo de transmitância térmica de paredes externas para a zona bioclimática 2 .

A partir dos valores calculados também se pode constatar o melhor desempenho do compósito 4 obtido a partir do sabugo de milho moído, usando a cola de madeira como aglutinante na formulação desenvolvida por Paiva et al. (2012). Esse resultado vem ao encontro de um estudo feito na região de Trás-osMontes e Alto Douro em Portugal onde são feitas construções de tabique (técnica portuguesa que usa sabugo de milho como material de enchimento para paredes externas). A pesquisa mostrou que o sabugo de milho é um resíduo agrícola com propriedades térmicas promissoras para ser usado em compósitos (PINTO et al., 2011). Para os autores, estrutura da camada mais interna se assemelha à microestrutura do poliestireno expandido (EPS), material sintético tradicionalmente usado com diversas finalidades.

Os resultados obtidos por Rout e Satapathy (2012), que usaram o resíduo casca de arroz, ou por Rosa et al. (2015), que desenvolveram um compósito com talos de girassol, cascas de arroz, gesso e juta, obtendo uma condutividade

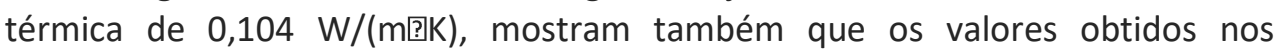
experimentos usando o resíduo sabugo de milho apresentam resultados melhores na função de isolamento térmico. 
Quadro 3 - Valores comparativos entre os dois tipos de parede adotados no estudo, sem e com o uso dos compósitos adotados na pesquisa

\begin{tabular}{|c|c|c|c|c|c|}
\hline $\begin{array}{c}\text { SISTEMA } \\
\text { AVALIADO }\end{array}$ & $\begin{array}{c}\mathbf{R}_{\mathbf{T}} \\
\left(\mathbf{m}^{2} \cdot \mathbf{K}\right) / \mathbf{W}\end{array}$ & $\begin{array}{c}\mathbf{U} \\
\mathbf{W} / \\
\left(\mathbf{m}^{2} \cdot \mathbf{K}\right)\end{array}$ & $\begin{array}{l}\text { ATENDIMENTO } \\
\text { DO PRÉ- } \\
\text { REQUISITO }^{1}\end{array}$ & $\begin{array}{l}\text { FSo } \\
(\%)\end{array}$ & $\begin{array}{l}\text { ATENDIMENTO } \\
\text { DO PRÉ- } \\
\text { REQUISITO }^{2}\end{array}$ \\
\hline $\begin{array}{l}\text { Parede de } \\
\text { blocos } \\
\text { vazados de } \\
\text { concreto }\end{array}$ & 0,352 & 2,844 & Não & 4,551 & Sim \\
\hline $\begin{array}{c}\text { Parede de } \\
\text { blocos } \\
\text { vazados de } \\
\text { concreto - } \\
\text { compósito } 1 \\
(0,059 \\
\text { W/mK) }\end{array}$ & 0,521 & 1,918 & Sim & 3,069 & Sim \\
\hline $\begin{array}{c}\text { Parede de } \\
\text { blocos } \\
\text { vazados de } \\
\text { concreto - } \\
\text { compósito } 2 \\
(0,082 \\
\text { W/mK) } \\
\end{array}$ & 0,472 & 2,117 & Sim & 3,388 & Sim \\
\hline $\begin{array}{l}\text { Parede de } \\
\text { blocos } \\
\text { vazados de } \\
\text { concreto - } \\
\text { compósito } 3 \\
(0,28 \mathrm{~W} / \mathrm{mK})\end{array}$ & 0,381 & 2,623 & Não & 4,197 & Sim \\
\hline $\begin{array}{c}\text { Parede de } \\
\text { blocos } \\
\text { vazados de } \\
\text { concreto - } \\
\text { compósito } 4 \\
(0,043 \\
\text { W/mK }) \\
\end{array}$ & 0,586 & 1,707 & Sim & 2,731 & Sim \\
\hline $\begin{array}{l}\text { Parede de } \\
\text { blocos } \\
\text { vazados de } \\
\text { cerâmica }\end{array}$ & 0,398 & 2,511 & Não & 4,018 & Sim \\
\hline $\begin{array}{c}\text { Parede de } \\
\text { blocos } \\
\text { vazados de } \\
\text { cerâmica - } \\
\text { compósito } 1 \\
(0,059 \\
\text { W/mK) }\end{array}$ & 0,562 & 1,779 & Sim & 2,846 & Sim \\
\hline $\begin{array}{c}\text { Parede de } \\
\text { blocos } \\
\text { vazados de } \\
\text { cerâmica - } \\
\text { compósito } 2 \\
(0,082 \\
\text { W/mK }) \\
\end{array}$ & 0,514 & 1,945 & Sim & 3,112 & Sim \\
\hline $\begin{array}{l}\text { Parede de } \\
\text { blocos } \\
\text { vazados de } \\
\text { cerâmica - }\end{array}$ & 0,426 & 2,347 & Sim & 3,755 & Sim \\
\hline
\end{tabular}




\begin{tabular}{|c|l|l|l|l|l|}
\hline $\begin{array}{c}\text { compósito 3 } \\
(0,28 \mathrm{~W} / \mathrm{mK})\end{array}$ & & & & & \\
\hline $\begin{array}{c}\text { Parede de } \\
\text { blocos }\end{array}$ & & & & & \\
$\begin{array}{c}\text { vazados de } \\
\text { cerâmica }-\end{array}$ & 0,626 & 1,598 & Sim & 2,556 & Sim \\
$\begin{array}{c}\text { compósito } 4 \\
(0,043\end{array}$ & & & & & \\
W/mK) & & & & & \\
\hline
\end{tabular}

$1-\mathrm{U} \leq 2,5 \mathrm{~W} /(\mathrm{m} 2 \cdot \mathrm{K})$ - valor limite de transmitância térmica de paredes externas para a zona bioclimática 2 (ABNT, 2013a, p. 27)

2 - FSO $\leq 5,0 \%$ - valor admissível do fator solar de elementos opacos (parede leve) conforme exigências para a zona bioclimática 2 (ABNT, 2005c, p. 22)

Fonte: Autoria própria (2017)

\section{CONSIDERAÇÕES FINAIS}

Os resíduos estão se tornando um problema ambiental cada vez mais sério, uma vez que são produzidos em grandes quantidades e alguns são de difícil decomposição.

Várias pesquisas têm investigado o desempenho ambiental, acústico e térmico de materiais pouco utilizados. Alguns compósitos não convencionais elaborados a partir de resíduos de indústrias de transformação e processamento agrícola estão sendo pesquisados, sendo que alguns dos materiais obtidos têm se caracterizado pelo desempenho semelhante aos comerciais.

Os resultados apresentados sugerem que o uso da casca de arroz e do sabugo de milho, tem um papel importante de isolamento térmico de enchimento. Além disso, esses resultados podem servir de orientação para o futuro das construções prediais no sentido de melhorar o isolamento térmico, assim como o aproveitamento de um resíduo agrícola. 


\title{
Thermal performance of masonry walls protected with coating of composites of agricultural residues
}

\begin{abstract}
The article aims to evaluate the use of agricultural waste in composites for thermal insulation for use in vertical fence systems in buildings, identifying the relevant norms for the southern region of Brazil. The survey had as a starting point the analysis of the results obtained in surveys where the thermal performance of agricultural residues were evaluated, focusing on the use of corn cobs and rice hull. Was simulated a masonry wall in concrete blocks and pottery, grouted on both sides with mortar joint, considering also the use of a composite layer under the mortar on one side of the wall. The various systems were evaluated and compared with the values of thermal transmittance and solar heat gain factor. The results obtained confirm the improving performance of the walls with the use of composites.
\end{abstract}

KEYWORDS: Agricultural waste. Composite. Thermal insulation. 


\section{REFERÊNCIAS}

ABNT. ASSOCIAÇÃO BRASILEIRA DE NORMAS TÉCNICAS. ABNT NBR 15220-1: 2005. Desempenho térmico de edificações Parte 1: Definições, símbolos e unidades. Rio de Janeiro, 2005a.

ABNT. ASSOCIAÇÃO BRASILEIRA DE NORMAS TÉCNICAS. ABNT NBR 15220-2: 2005. Desempenho térmico de edificações Parte 2: Métodos de cálculo da transmitância térmica, da capacidade térmica, do atraso térmico e do fator solar de elementos e componentes de edificações. Rio de Janeiro, 2005b.

ABNT. ASSOCIAÇÃO BRASILEIRA DE NORMAS TÉCNICAS. ABNT NBR 15220-3: 2005. Desempenho térmico de edificações Parte 3: Zoneamento bioclimático brasileiro e diretrizes construtivas para habitações unifamiliares de interesse social. Rio de Janeiro, 2005c.

ABNT. ASSOCIAÇÃO BRASILEIRA DE NORMAS TÉCNICAS. ABNT NBR 15575-4: 2013. Edificações habitacionais - Desempenho Parte 4: Requisitos para os sistemas de vedações verticais internas e externas - SVVIE. Rio de Janeiro, $2013 \mathrm{a}$.

ABNT. ASSOCIAÇÃO BRASILEIRA DE NORMAS TÉCNICAS. ABNT NBR 15575-5: 2013. Edificações habitacionais - Desempenho Parte 5: Requisitos para os sistemas de coberturas - SVVIE. Rio de Janeiro, 2013b.

AMICK, J. A. Purification of rice hulls as a sourge of solar grade silicon for solar cells. Journal Electrochemistry Society, v. 129, n. 4, p. 864-866, 1982. crossref

ARMESTO, L.; BAHILLO, A.; VEIJONEN, K.; CABANILLAS, A.; OTERO, J. Combustion behaviour of rice husk in a bubbling fluidised bed. Biomass and Bioenergy, v. 23, n. 3, p. 171-179, 2002. crossref

ASDRUBALI, F., D'ALESSANDRO, F., SCHIAVONI, S. A review of unconventional sustainable building insulation materials. Sustainable Materials and Technologies, v. 4, p. 1-17, 2015. crossref

BARBOSA, T. G. Cultivares de milho a diferentes populações de plantas e épocas de semeadura em Vitória da Conquista-BA. 2011. 73f. Dissertação (Mestrado em Agronomia) - Programa de Pós-Graduação em Agronomia, Universidade Estadual do Sudoeste da Bahia, Vitória da Conquista, 2011.

BEZERRA, I. M. T. Cinza da casca do arroz utilizada em argamassas de assentamento e revestimento. 2010. 108p. Dissertação (Mestrado em Engenharia Civil) - Programa de Pós-Graduação em Engenharia Civil e Ambiental, Universidade Federal de Campina Grande, Campina Grande, 2010. 
BORGNAKKE, C.; SONNTAG, R. E. Fundamentos da termodinâmica. São Paulo: Blücher, 730 p, 2013.

CALLISTER JR., W. D. Fundamentos da ciência e engenharia de materiais: uma abordagem integrada. Rio de Janeiro: LTC, 2014.

CHAVES, T. F.; QUEIROZ, Z. F.; SOUZA, D. N. R.; GIRÃO, J. H. S.; RODRIGUES, E. A. Uso da cinza da casca do arroz (CCA) obtida da geração de energia térmica como adsorvente de Zn(II) em soluções aquosas. Química Nova, v. 32, n. 6, p. 13781383, 2009.

crossref

COMPANHIA NACIONAL DE ABASTECIMENTO. Acompanhamento da safra brasileira de grãos, safra 2016/17. Brasília: CONAB, 2017. Disponível em: <http://www.conab.gov.br/OlalaCMS/uploads/arquivos/17_07_12_11_17_01_bo letim_graos_julho_2017.pdf >. Acesso em 21 jul. 2017.

CRUZ, M. P.; FERREIRA, R. J. P.; MARINHO, G. S. Aplicação de resíduo industrial para isolamento térmico de ambientes. In: XXIX Encontro Nacional de Engenharia de Produção, 24, 2009, Salvador. Anais... Salvador: ABEPRO, 2009. Disponível em: <http://www.abepro.org.br/biblioteca/enegep2009_TN_STP_099_668_14522.pd f>. Acesso em: 07 dez. 2016.

DELLA, V. P., KUHN, I., HOTZA, D. Caracterização de cinza de casca de arroz para uso como matéria-prima na fabricação de refratários de sílica. Química Nova, v. 24, n. 6, p. 778-782, 2001. crossref

EUROPEAN COMMISSION. Buildings. Bruxelas: 2016. Disponível em: < http://ec.europa.eu/energy/en/topics/energy-efficiency/buildings $>$. Acesso em: 17 jul. 2016.

FERNANDES, A. Sintese de Zeólita e Wolastonita a partir de cinza de casca de arroz. 2006. 98p. Tese (Doutorado em Ciências dos Materiais) - Área de Tecnologia Nuclear-Materiais, Instituto de Pesquisas Energéticas e Nucleares, Universidade de São Paulo, São Paulo, 2006.

FERREIRA, S. F. Caracterização de produtos cárneos desenvolvidos com farinha de sabugo de milho (Zea mays). 2014. 93f. Dissertação (Mestrado em Ciência e Tecnologia dos Alimentos) - Programa de Pós-Graduação em Ciência e Tecnologia dos Alimentos, Universidade Federal de Santa Maria, Santa Maria, 2014. 
FAO. Food and Agriculture Organization of the United Nations. - Statistics FAOSTAT. Food and agricultural commodities production. 2012. Disponível em: <http://faostat.fao.org/site/339/default.aspx>. Acesso em: 10 dezembro 2015.

FROTA, A. B.; SCHIFFER, S. R. Manual de conforto térmico. São Paulo: Nobel, 2003. 243 p.

GIL, A. C. Como elaborar projetos de pesquisa. São Paulo: Atlas, 2010.

IBGE. Instituto Brasileiro de Geografia e Estatística. Estatística da Produção Agrícola. Rio de Janeiro: IBGE, 2017. Disponível em:

<ftp://ftp.ibge.gov.br/Producao_Agricola/Fasciculo_Indicadores_IBGE/estProdAg r_201701.pdf>. Acesso em: 11 jun. 2017.

INSTITUTO DE PESQUISA ECONÔMICA APLICADA - IPEA. Diagnóstico dos Resíduos Orgânicos do Setor Agrossilvopastoril e Agroindústrias Associadas. Brasília: IPEA, 2012.

KORJENIC, A.; PETRÁNEK, V.; ZACH, J.; HROUDOVÁ, J. Development and performance evaluation of natural thermal-insulation materials composed of renewable resources. Energy and Buildings, v. 43, n. 9, p. 2518-2523, 2011.

crossref

MATI-BAOUCHE, N.; DE BAYNAST, H.; LEBERT, A.; SUN, S.; LOPEZ-MINGO, C. J. S.; LECLAIRE, P.; MICHAUD, P. Mechanical, thermal and acoustical characterizations of an insulating bio-based composite made from sunflower stalks particles and chitosan. Industrial Crops and Products, v. 58, p. 244-250, 2014. crossref

MENDES, R. F.; MENDES, L. M.; GUIMARÃES JUNIOR, J. B.; MORI, F. A.; CÉSAR, A. A. da $S$. Efeito da incorporação de casca de café nas propriedades físicomecânicas de painéis aglomerados de Eucalyptus urophylla S.T. Blake. Ciência e Agrotecnologia, Lavras, v.34, n.3, p.610-617, maio/jun, 2010b.

MIGUEL, P. A. C. (Org.). Metodologia de pesquisa em engenharia de produção e gestão de operações. Rio de Janeiro: Elsevier, 2012.

MISHRA, P.; CHAKRAVERTY, A.; BANERJEE, H. D. Studies on physical and thermal properties of rice husk related to its industrial application. Journal of Materials Science, v. 21, p. 2129-2132, 1986. crossref

NEIRA, D. S. M. Fibras de sisal (Agave sisalana) como isolante térmico de tubulações. 2005. 79 f. Dissertação (Mestrado em Engenharia Mecânica) Universidade Federal do Rio Grande do Norte - UFRN, 2005. 
PAIVA, A.; PEREIRA, S.; SÁ, A.; CRUZ, D.; VARUM, H.; PINTO, J. A contribution to the thermal insulation performance characterization of corn. Energy and Buildings, n. 45, p. 274-279, 2012.

PANYAKAEW, S.; FOTIOS, S. New thermal insulation boards made from coconut husk and bagasse. Energy and Buildings, v. 43, n. 7, p. 1732-1739, 2011.

crossref

PINTO, J.; PEREIRA, H.; VILELA, P.; JACINTO, C.; VIEIRA, J.; PAIVA, A.; PEREIRA, S.; FERREIRA, J.; CUNHA, V. M. C. F.; VARUM, H. Camada de regularização com agregado de granulado de caroço da espiga de milho. In: 4o Congresso Português de Argamassas e ETICS, 4, 2012, Coimbra. Anais... Coimbra: APFAC, 2012.

PINTO, J., PAIVA, A., VARUM, H., COSTA, A., CRUZ, D., PEREIRA, S., FERNANDES, L., TAVARES, P., AGAWAL, J. Corn's cob as a potential ecological thermal insulation material. Energy and Buildings, v. 43, p. 1985-1990, 2011. crossref

ROSA, L. C.; SANTOR, C. G.; LOVATO, A.; ROSA, C. S.; GÜTHS, S. Use of rice husk and sunflower stalk as a substitute for glass wool in thermal insulation of solar collector. Journal of Cleaner Production, v. 104, p. 90-97, 2015. crossref

ROUT, A. K.; SATAPATHY, A. Computational and experimental investigation on thermal insulation capabilities of rice husk filled epoxy

composites. Computational Thermal Sciences, v. 4, n. 2, p. 107-114, 2012.

crossref

TAMANINI, C.; HAULY, M. C. D. O. Resíduos agroindustriais para produção biotecnológica de xilitol. Ciências de Alimentos, Londrina, PR, v. 25, n. 4, p. 315330,2004 . crossref

TEIXEIRA, M. G.; SANTOS JUNIOR, E. C.; COUTO, E. C. S. Aplicação de conceitos da ecologia industrial no design de produtos em eco-compósito de resíduos particulados e pedaços descartados de madeira. Gestão Industrial, v. 12, n. 1, p. 200-2019, 2016. crossref

TURCO, G. M. S. Produção e composição física da planta de milho para silagem, cultivado em dois níveis de adubação associado a dois espaçamentos entre linhas e duas densidades de plantio. 2011. 65f. Dissertação (Mestrado em Agronomia) - Programa de Pós-Graduação em Agronomia - Produção Vegetal, Universidade Estadual do Centro-Oeste, Guarapuava, 2011.

VIEIRA, A. C. Caracterização da biomassa proveniente de resíduos agrícolas para geração de energia. 2012. 56f. Dissertação (Mestrado em Energia na Agricultura) 
- Pós-Graduação em Energia na Agricultura, Universidade Estadual do Oeste do Paraná, Cascavel, 2012.

UNEP. United Nation Environment Programme. State of play of suistainable building in France. Paris: 2012. Disponível em:

<http://www.unep.org/sbci/pdfs/SoPFrance-Final.pdf >. Acesso em: 15 jul. 2016.

U.S. DEPARTMENT OF ENERGY. Building energy data book. Silver Spring: 2012. Disponível em: < http://buildingsdatabook.eren.doe.gov/Chapterlntro1.aspx> . Acesso em: 15 jul. 2016.

ROSA, F. S. ; SCHERER, M. J. Desempenho térmico de paredes de alvenaria protegidas com revestimento de compósitos de resíduos agrícolas. R. Gest. Industr., Ponta Grossa, v. 14, n. 2, p. 96-113, abr./jun. 2018. Disponível em: <https://periodicos.utfpr.edu.br/rgi>. Acesso em: XXX

Correspondência:

Fábio Severo da Rosa

Rua Silva Jardim, 2149, Apto. 404, Santa Maria, Rio Grande do Sul, Brasil.

Direito autoral: Este artigo está licenciado sob os termos da Licença Creative Commons-Atribuição 4.0 Internacional.

\section{(c) (1)}

